\begin{tabular}{lr}
\hline Jurnal Abdimas llmiah & JURNAL ABDIMAS ILMIAH CITRA BAKTI \\
Citra Bakti & Volume 2, Nomor 1, April 2021 \\
(JAICB) & ISSN 2721-9178 \\
\hline
\end{tabular}

\title{
PELATIHAN PEMBUATAN PRODUK HERBAL INSTAN UNTUK PENINGKATAN POLA HIDUP SEHAT
}

\author{
Nike Herpianti Lolok¹), Bai Athur Ridwan²), Dwi Syahfitra Ramadhan³), Wa Ode \\ Yuliastri $^{4)}$ \\ Program Studi Farmasi, Universitas Mandala Waluya \\ ${ }^{1)}$ nikeherpianti.apt@gmail.com, ${ }^{2}$ baiathurridwan05@gmail.com, ${ }^{3)}$ ditrarmdhn@gmail.com, \\ 4)waodeyuliastri@yahoo.com
}

\section{Histori artikel}

Received:

07 Februari 2021

Accepted:

11 April 2021

Published:

19 April 2021

\begin{abstract}
Abstrak
Warisan budaya bangsa Indonesia yang masih digunakan hingga saat ini khususnya dalam pemeliharaan dan peningkatan kesehatan serta pencegahan dan pengobatan penyakit adalah penggunaan obat tradisional. Salah satu tanaman yang dapat dimanfaatkan adalah temulawak (Curcuma Xanthorrhiza) yang dapat diolah sebagai minuman instan dalam bentukserbuk yang mudah dan praktis dalam penyajiannya serta dapat memperpanjang umur simpan. Namun sebagian besar masyarakat belum pernah memperoleh pelatihan tentang pemanfaatan produk herbal untuk peningkatan pola hidup sehat. Untuk mengatasi masalah tersebut maka perlu dilakukan suatu kegiatan dengan tujuan untuk meningkatkan keterampilan masyarakat dalam memanfaatkan tanaman obat secara praktis dan mudah sebagai bagian dalam peningkatan hidup sehat. Kegiatan ini dilaksanakan di Desa Boro-Boro Lameuru Kecamatan Ranomeeto Barat Kabupaten Konawe Selatan, Sulawesi Tenggara dengan melibatkan masyarakat dengan menggunakan metode pelatihan dengan cara mendemonstrasikan pembuatan minuman instan. Hasil kegiatan pelatihan diperoleh produk herbal berbentuk serbuk temulawak berwarna kuning, aroma khas temulawak dan tekstur yang sedikit kasar dengan ukuran yang homogen serta masyarakat suka terhadap produk yang dihasilkan. Temulawak juga diketahui memiliki khasiat meningkatkan sistem imun, menyegarkan tubuh, memperlancar metabolisme, menyehatkan fungsi hati, menambah nafsu makan, sebagai imunomodulator, hepatoprotektor, dan dapat meningkatkan daya tahan dan stamina tubuh. Kegiatan ini dapat meningkatkan keterampilan masyakat dalam memanfaatkan bahan alam yang tersedia untuk meningkatkan kesehatan atau mencegah paparan dari penyakit terutama dimasa pandemi seperti saat ini.
\end{abstract}

Kata-kata Kunci: produk herbal instan, pola hidup sehat 
Abstract. The cultural heritage of the Indonesian people that is still used today, especially in the maintenance and improvement of health as well as the prevention and treatment of diseases is the use of traditional medicines. One of the plants that can be used is ginger (Curcuma Xanthorrhiza) which can be processed as an instant drink in powder form which is easy and practical to serve and can extend shelf life. However, most people have never received training on the use of herbal products to promote healthy lifestyles. To overcome this problem, it is necessary to carry out an activity to improve the skills of the community in using medicinal plants practically and easily as part of improving a healthy life. This activity was carried out in Boro-Boro Lameuru Village, Ranomeeto Barat District, South Konawe Regency, Southeast Sulawesi by involving the community using training methods. In the results of the training activities, the manufacture of instant beverages with raw materials obtained ginger powder ginger yellow color, distinctive aroma of ginger and a slightly rough texture with homogeneous size and people like the products produced. Temulawak is also known to have the property of increasing the immune system, refreshing the body, accelerating metabolism, healthy liver function, increasing appetite, as an immunomodulator, hepatoprotective, and can increase endurance and stamina. This activity can improve community skills in utilizing available natural materials to improve health or prevent exposure to diseases, especially during a pandemic such as today.

Keywords: instant drinks, curcuma xanthorrhiza, healthy drinks, boro-boro lameuru village

\section{PENDAHULUAN}

Warisan budaya bangsa Indonesia yang masih digunakan hingga saat ini khususnya dalam pemeliharaan dan peningkatan kesehatan serta pencegahan dan pengobatan penyakit salah satunya adalah penggunaan obat tradisional (OT) (Kemenkes RI, 2017). Berdasarkan hasil Riset Kesehatan Dasar (Riskesdas) Badan Litbangkes, (2013) menyatakan bahwa terdapat 49,0\% rumah tangga di Indonesia memanfaatkan ramuan tanaman berkhasiat obat sebagai penanganan masalah kesehatan. Hal ini tidak lepas dari produksi tanaman berkhasiat obat yang tiap tahun terus mengalami peningkatan (BPS, 2019). Seiring dengan kemajuan ilmu pengetahuan dan teknologi yang semakin pesat, OT juga samakin mengalami perkembangan mulai dari aspek pembuktian khasiat dan keamanan, mutu, bentuk sediaan, cara pemberian, pengemasan hingga teknologi produksi (Kemenkes RI, 2017).

Produk suplemen yang dapat meningkatkan kesehataan baik dalam bentuk makanan dan minuman saat ini banyak tersedia dengan berbagai merek dan bentuk, seperti dalam bentuk cair, serbuk instan ataupun tablet. Saat ini masyarakat cenderung lebih suka menggunakan produk yang kemasan dan penyajiannya lebih praktis dan cepat. Salah satu contoh tanaman yang diolah sebagai produk minuman instan adalah rimpang jahe yang tersedia dalam bentuk serbuk, cairan bahkan dalam bentuk tablet sebagai produk minuman kesehatan (Sukmawati \& Merina, 2019). Selain itu tanaman yang bisa dimanfaatkan sebagai obat tradisional adalah temulawak (Curcuma Xanthorrhiza) (Izazi \& Kusuma, 2020). Dilihat dari tingkat produksi, temulawak (Curcuma Xanthorrhiza) di Indonesia tahun 2019 mengalami peningkatan sebesar $13,72 \%(29.637 .119 \mathrm{Kg})$ dari tahun sebelumnya (BPS, 2019).

Temulawak memiliki khasiat dalam peningkatan sistem imun, menyegarkan tubuh, memperlancar metabolisme, menyehatkan fungsi hati, menambah nafsu makan, sebagai 
imunomodulator dan hepatoprotektor. Selain itu juga dapat meningkatkan daya tahan dan stamina tubuh (Izazi \& Kusuma, 2020). Konsumsi herbal dan suplemen kesehatan perlu dibudayakan oleh masyarakat terutama pada masa pandemi COVID-19 ini untuk meningkatkan imunitas (BPOM, 2020).

Berdasarkan hasil observasi, masyarakat di Desa Boro-Boro Lameuru sebagian besar masih memanfaatkan tanaman yang berkhasiat obat dalam menangani masalah kesehatan karena mudah ditemukan dan tidak memerlukan biaya mahal. Khasiat tanaman herbal dapat diperoleh jika dapat diolah dengan baik namun jika tanaman obat tidak diolah dengan cara yang baik dan benar maka akan mengurangi khasiat dari tanaman tersebut. Salah satu bentuk pengolahan tanaman obat dengan keunggulan dapat memperpanjang waktu simpan, praktis dan cepat dalam penyajian adalah dibuat dalam bentuk serbuk sebagai minuman instan herbal. Namun kenyataannya masyarakat di Desa Boro-Boro Lameuru belum pernah memperoleh pelatihan terkait dengan pengolahan tanaman obat dalam bentuk serbuk. Oleh karena itu dilakukan kegiatan pengabdian kepada masyarakat ini dengan tujuan untuk meningkatkan keterampilan masyarakat dalam mengolah tanaman obat menjadi produk herbal yang praktis dan mudah saat digunakan.

\section{METODE PELAKSANAAN}

Kegiatan pengabdian kepada masyarakat (PKM) dilaksanakan di Desa Boro-Boro Lameuru. Pelaksanaan kegiatan PKM diawali dengan pembukaan dan penerimaan dari pemerintah Desa sebagaimana terlihat pada gambar 1 berikut.

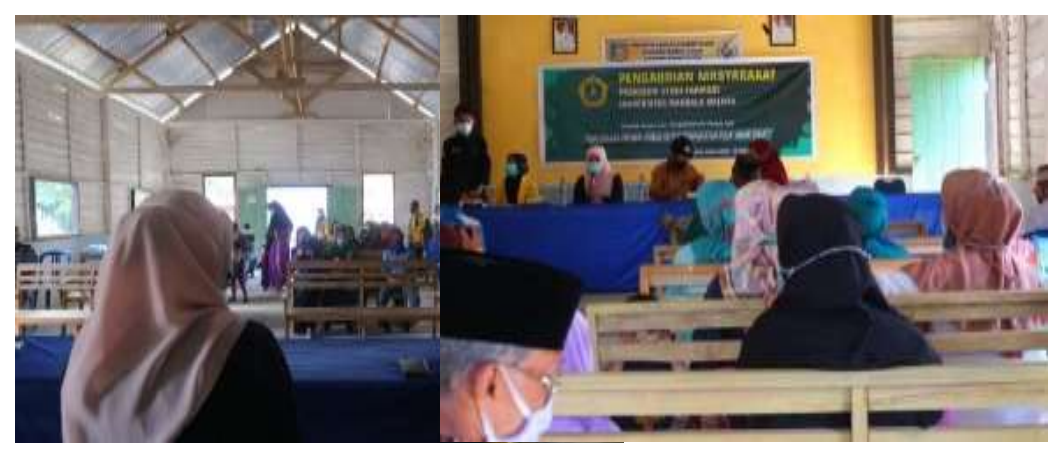

Gambar 1. Penerimaan Dari Pemerintah Desa

Adapun metode yang digunakan pada kegiatan pengabdian kepada masyarakat di Desa Boro-Boro Lameuru yaitu dilakukan dengan cara pelatihan dengan cara mendemonstrasikan pembuatan minuman instan. Kegiatan pelatihan diawali dengan pemaparan mengenai kelebihan dari serbuk instan yakni mudah dalam pengolahannya dan tidak membutuhkan waktu dalam penyajian (Sayuti \& Permata, 2016) Kemudian dilanjutkan dengan melakukan praktek atau pelatihan pengolahan tanaman herbal menjadi minuman instan dalam bentuk serbuk dengan bahan baku rimpang temulawak. Adapun proses pembuatan minuman instan dari rimpang temulawak ini yaitu sebagai berikut: 
1. Penyiapan alat dan bahan

Alat dan bahan yang disiapkan yaitu terdapat pada tabel 1 berikut.

\begin{tabular}{ll}
\multicolumn{2}{c}{ Tabel 1. Alat dan Bahan } \\
\hline \multicolumn{1}{c}{ Alat } & \multicolumn{1}{c}{ Bahan } \\
\hline Kompor 1 buah & Temulawak $500 \mathrm{mg}$ \\
\hline Blender 1 buah & Daun pandan wangi secukupnya \\
\hline Panci 1 buah & Air $800 \mathrm{cc}$ \\
\hline Wajan 1 buah & Gula pasir $1 \mathrm{~kg}$ \\
\hline Pisau 2 buah & \\
\hline saringan 1 buah & \\
\hline Timbangan \\
makanan 1 buah
\end{tabular}

2. Rimpang temulawak dicuci dengan air bersih.

3. Rimpang temulawak ditimbang $500 \mathrm{~g}$ dan gula pasir $1 \mathrm{~kg}$

4. Rimpang temulawak dirajang dan dihaluskan dengan menggunakan blender yang ditambahkan $800 \mathrm{~mL}$ air.

5. Diambil sari temulawak dengan cara disaring menggunakan kain kasa atau alat penyaring dan ampasnya dibuang.

6. Direbus sari temulawak dan ditambahkan gula pasir $1 \mathrm{~kg}$ serta daun pandan secukupnya hingga gula larut sempurna.

7. dilakukan penyaringan kembali untuk menghilangkan kotoran yang masih tertinggal.

8. Filtrat yang diperoleh, dipindahkan kedalam wajan agar wadah lebih lebar untuk proses kristalisasi yang dilakukan dengan cara perebusan dengan menggunakan api kecil sehingga suhu kurang dari $100{ }^{\circ} \mathrm{C}$ dan dilakukan pengadukan secara terus menerus sampai terbentuk kristal atau serbuk.

9. Serbuk didinginkan kemudian dihaluskan dengan blender dan disaring agar bentuk serbuknya seragam.

10. Dilakukan pengemasan dengan plastik.

Produk yang dihasilkan harapannya dapat digunakan sebagai kebutuhan pribadi atau orang lain dalam meningkatkan kesehatan dari berbagai khasiat yang dapat diperoleh dari temulawak. 


\section{HASIL DAN PEMBAHASAN}

Hasil

Hasil pengolahan rimpang temulawak menjadi bentuk serbuk sebagai minuman instan herbal dapat dilihat pada Gambar 2 berikut.

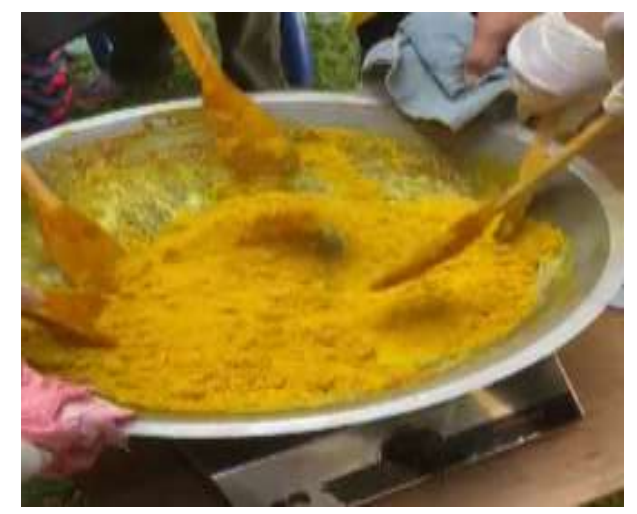

Gambar 2. Serbuk Temulawak

Penilaian secara organoleptis serbuk temulawak memiliki warna kuning, aroma khas temulawak, dan memiliki tekstur yang sedikit kasar dengan ukuran yang homogen. Selain itu para peserta juga suka terhadap serbuk temulawak yang dibuat.

\section{Pembahasan}

Pengolahan minuman instan dalam bentuk serbuk dilakukan dengan cara mendemonstrasikan atau mempraktekkan cara pengolahan minuman instan dihadapan para peserta dan tidak melibatkan partisipasi peserta secara langsung dalam pembuatan minuman instan. Walaupun demikian, Selama kegiatan berlangsung masyarakat yang ikut dalam kegiatan ini sangat antusias dengan mengajukan beberapa pertanyaan yang berkaitan dengan beberapa tanaman obat, cara pengolahan menjadi produk minuman instan, dan manfaat atau khasiat yang akan diperoleh jika dikonsumsi. Dalam kegiatan ini pula tidak dilakukan pengukuran tingkat pengetahuan masyarakat terkait dengan pengolahan atau pemanfaatan tanaman obat sebagai minuman instan dalam bentuk serbuk.

Dalam pengolahan minuman instan sebagaimana yang dilakukan pada kegiatan ini, bahan baku yang digunakan adalah rimpang temulawak dan bahan tambahan seperti gula pasir dan daun pandan. Penambahan gula pada pembuatan minuman instan berfungsi sebagai pemanis dan pengikat sedangkan daun pandan berfungsi untuk menutupi aroma yang kurang enak dari temulawak dan untuk mengurangi rasa getir dapat ditambahkan dengan jahe, kencur, atau asam jawa (Septiana, 2020). Campuran bahan kemudian direbus dengan api kecil sekitar kurang dari $100^{\circ} \mathrm{C}$ sehingga membutuhkan waktu cukup lama $( \pm 40$ menit) sampai terbentuk serbuk. Menurut Moehady (2015) menyatakan bahwa pada suhu $45-60{ }^{\circ} \mathrm{C}$ sudah mencapai kadar air kritik sehingga pengeringan berjalan dengan sempurna dan dapat digerus untuk memperoleh serbuk halus. Terbentuknya serbuk tersebut diikuti 
dengan penurunan bobot atau penyusutan karena penguapan yang terjadi pada saat proses pemanasan dan terbentuknya serbuk juga karena sifat gula yang kembali mengkristal setelah pemanasan jika dalam kondisi $\mathrm{pH}$ basa $(\mathrm{pH}>6,7)$ serta menghindari suhu pemanasan yang terlalu tinggi agar tidak mengakibatkan kegosongan (Sukmawati \& Merina, 2019).

Terlepas dari hal tersebut, Pemanfaatan tanaman obat yang diolah sebagai minuman instan dalam bentuk serbuk bisa menjadi salah satu pilihan bagi masyarakat untuk meningkatkan pola hidup sehat dari berbagai khasiat yang diperoleh dari tanaman obat, misalnya untuk menjaga imunitas agar tetap tinggi sangat penting dilakukan sebagai sistem pertahanan yang berperan dalam mengenal, menghancurkan, serta menetralkan bendabenda asing yang berpotensi menimbulkan penyakit (Izazi \& Kusuma, 2020). Banyak hal yang bisa dilakukan untuk meningkatkan imunitas, salah satunya dengan mengkonsumsi obat tradisional seperti temulawak (Curcuma Xanthorrhiza) yang dapat dibuat sebagai minuman instan untuk kesehatan seperti menambah nafsu makan, penawar racun, antiinflamasi dan sebagai antioksidan. Hal ini tidak lepas dari kandungan kimia yang terdapat pada tanaman tersebut yaitu minyak atsiri, kurkumin, serat, dan senyawa kimia alkaloid, flavonoid, fenolik, glikosida, steroid, serta triterpenoid (Sastrawidana \& Saraswati, 2020).

Pemilihan temulawak menjadi hal yang perlu diperhatikan agar khasiat yang diperoleh lebih maksimal, seperti waktu pemanenan temulawak agar diperoleh produk yang maksimal harus memperhatikan beberapa hal yakni temulawak di panen pada umur 10-12 bulan dengan ciri batang dan daun sudah mengering, kulit rimpang tidak mudah terkelupas dan beraroma menyengat yang khas (aromatis) tingkat kematangan, semakin matang tanaman temulawak maka kandungan pati dari temulawak semakin kompleks (Khamidah, Antarlina, \& Sudaryono, 2017).

Minuman serbuk instan adalah minuman siap saji yang langsung dapat diseduh dengan air sehingga menghemat waktu dalam penyajiannya. Menurut Cahyaningrum, (2020) menyatakan bahwa minuman instan dalam bentuk serbuk memiliki kriteria yang baik jika bau, warna, dan rasa sebanding dengan produk segar. Secara organoleptis, minuman instan serbuk temulawak berwarna kuning karena kandungan kurkumin dan demetoksikurkumin pada temulawak (Setyowati \& Suryani, 2013).

Kurkumin merupakan salah satu komponen aktif pada rimpang temulawak yang berperan sebagai antioksidan yang bertanggung jawab dalam pertahanan tubuh akibat dari radikal bebas (Rosidi, Khomsan, Setiawan, Riyadi, \& Briawan, 2014). Selain itu kandungan flavonoid juga berperan dalam meningkatkan sistem imunitas tubuh dan ciri bahan herbal yang mengandung flavonoid yaitu ketika diaduk menghasilkan busa namun bisa rusak bahkan hilang jika terkena air mendidih (Sukmawati \& Merina, 2019). Oleh karena itu untuk memperoleh manfaat optimal dari minuman instan temulawak dapat dilakukan dengan cara 
diseduh menggunakan air yang tidak terlalu panas $\left(<100^{\circ} \mathrm{C}\right)$ agar kandungan kimianya tidak hilang atau rusak sehingga manfaat sebagai minuman kesehatan dapat optimal. Akan tetapi minuman instan temulawak ini tidak disarankan penggunaannya untuk orang yang mengalami diabetes melitus atau memiliki riwayat diabetes melitus karena mengandung bahan tambahan gula.

Selain dari bahan baku temulawak, minuman instan juga dapat dibuat dari bahan alam lain seperti jahe, kencur, kunyit, dan lengkuas. Manfaat atau khasiat dari masingmasing bahan alam tersebut yaitu jahe memiliki manfaat kesehatan untuk mengobati asma, sakit tenggorokan, masuk angin, mual-mual, mengobati sakit pinggang, dan mengatasi nyeri pada tulang. Kencur secara empirik digunakan untuk mengatasi batuk, infeksi bakteri, disentri, sakit perut, obat asma dan sebagai anti jamur. Kunyit memiliki manfaat sebagai antioksidan, mencegah leukemia, penuaan, sakit maag dan untuk diet. Sedangkan lengkuas dapat mencegah radang, luka lambung, obat diare, dan radang telinga (Sastrawidana \& Saraswati, 2020).

Dari berbagai informasi yang telah disampaikan kepada masyarakat di Desa BoroBoro Lameuru diharapkan dapat menambah keterampilan tentang pengolahan bahan alam sebagai obat tradisional yang efektif dan efisien.

\section{KESIMPULAN}

Kesimpulan dari hasil kegiatan pengabdian kepada masyarakat ini adalah minuman instan dari bahan baku temulawak diolah dengan prinsip kristalisasi sehingga terbentuk serbuk yang mudah dan praktis dalam penyajiannya serta dapat memperpanjang umur simpan. Serbuk temulawak yang terbentuk yaitu berwarna kuning, aroma khas temulawak dan teksturnya sedikit kasar dengan ukuran yang homogen dan. Temulawak memiliki kandungan kimia kurkumin yang berfungsi sebagai penangkal radikal bebas yang dapat menyebabkan penyakit dan senyawa flavonoid yang dapat meningkatkan sistem imun dan stamina tubuh. Dalam penyajian minuman instan temulawak diseduh dengan menggunakan air panas kurang dari $100^{\circ} \mathrm{C}$ agar komponen kimia yang terdapat pada temulawak tidak rusak atau hilang dan tidak disarankan untuk digunakan oleh individu yang memiliki riwayat diabetes karena mengandung kadar gula yang tinggi.

\section{DAFTAR PUSTAKA}

Badan Litbangkes. (2013). Riset Kesehatan Dasar. Jakarta.

BPOM. (2020). Bijak Manfaatkan Obat Herbal dan Suplemen Kesehatan untuk Daya Tahan Tubuh Menghadapi Pandemi COVID-19. Retrieved January 16, 2021, from https://www.pom.go.id/new/view/more/berita/18484/Bijak-Manfaatkan-Obat-Herbal-danSuplemen-Kesehatan-untuk-Daya-Tahan-Tubuh-Menghadapi-Pandemi-COVID-19.html

BPS. (2019). Produksi Tanaman Biofarmaka (Obat) 2017-2019. Retrieved January 16, 2019, from https://www.bps.go.id/indicator/55/63/1/produksi-tanaman-biofarmaka-obat-.html 
Cahyaningrum, P. L. (2020). Analisis Proksimat Serbuk Instan Kombinasi Rimpang Temulawak (Curcuma Xanthorrhiza Roxb.) dan Daun Anting-Anting (Acalypha indica L.). Widya Kesehatan, 2(1), 1-10.

Izazi, F., \& Kusuma, A. (2020). Hasil Responden Pengetahuan Masyarakat Terhadap Cara Pengolahan Temulawak (Curcuma Xanthorrhiza) dan Kencur (Kaemferia galanga) Sebagai Peningkatan Imunitas Selama COVID-19 dengan Menggunakan Kedekatan Konsep Program Leximancer. Journal of Pharmacy and Science, 5(2), 93-97.

Kemenkes RI. (2017). Farmakope Herbal Indonesia Edisi II (II). Jakarta: Kementerian Kesehatan Republik Indonesia.

Khamidah, A., Antarlina, S. S., \& Sudaryono, T. (2017). Ragam Produk Olahan Temulawak Untuk Mendukung Keanekaragaman Pangan. Jurnal Penelitian Dan Pengembangan Pertanian, 36(1), 1. https://doi.org/10.21082/jp3.v36n1.2017.p1-12

Moehady, B. I. (2015). Serbuk Temulawak Sebagai Bahan Baku Minuman. In Prosiding Industrial Research Workshop and National Seminar (Vol. 6, pp. 55-60).

Rosidi, A., Khomsan, A., Setiawan, B., Riyadi, H., \& Briawan, D. (2014). Potensi Temulawak (Curcuma xanthorrhiza Roxb) Sebagai Antioksidan. In Prosiding Seminar Nasional \& Internasional.

Sastrawidana, I. D. K., \& Saraswati, L. P. A. (2020). Pemanfaatan Tanaman Biofarmaka Sebagai Bahan Jamu Serbuk Untuk Meningkatkan Imun Tubuh. Proceeding Senadimas Undiksha, 1117.

Septiana, A. T. (2020). The Effect of Addition of Ginger Extract and Kencur Extract on the Physicochemical Properties of Instant Temulawak and the Sensory Properties of the Beverage. Jurnal Gizi Dan Pangan Soedirman, 3(2), 157-166.

Setyowati, A., \& Suryani, C. L. (2013). Peningkatan kadar kurkuminoid dan aktivitas antioksidan minuman instan temulawak dan kunyit. Agritech, 33(4), 363-370.

Sukmawati, W., \& Merina. (2019). Pelatihan Pembuatan Minuman Herbal Instan Untuk Meningkatkan Ekonomi Warga. Jurnal Pengabdian Kepada Masyarakat, 25(4), 210215. 